\title{
Investigation of the Turn-Off Characteristics of a GTO Thyristor in an Inductive-Based Pulse Forming Network
}

\author{
John G. Ciezki and Thomas E. Salem \\ Electrical \& Computer Eng. Dept. \\ U.S. Naval Academy \\ Annapolis, MD 21402 \\ (ciezki, salem)@usna.edu
}

\begin{abstract}
This paper introduces a test circuit that is used to study the turn-off characteristics of a GTO thyristor when used as an opening switch. Specifically a safe-operating-area has been identified which demonstrates that a particular GTO device can successfully turn off as much as three times the maximum rated interruptible current. The text examines mechanisms for GTO turn-off failure and proposes follow-on research initiatives.
\end{abstract}

\section{INTRODUCTION}

The Department of Defense continues to actively research railgun technology in order to field operational weapons to enhance warfighting capabilities of the U.S. Navy and Army. This is underscored by the January, 2008 record-setting test of a $32 \mathrm{MJ}$ railgun at the Naval Surface Warfare Center (NSWC) in Dahlgren, Virginia. A shipboard railgun system at the $64 \mathrm{MJ}$ level has the potential to fire projectiles on the order of $20 \mathrm{~kg}$ at muzzle velocities greater than $2500 \mathrm{~m} / \mathrm{s}$ and reach targets in excess of 200 nautical miles [1]. In comparison, the current MK 45 5-inch deck gun fires a highexplosive $32 \mathrm{~kg}$ projectile at a maximum muzzle velocity of $808 \mathrm{~m} / \mathrm{s}$ and has a maximum effective range of about 13 nautical miles. The railgun requires no explosives to fire the projectile and thus no explosive rounds are required to be stored in the ship's magazine.

One of the key technical challenges to integrating a practical railgun on board a warship is the physical size of the system, including the energy storage unit, pulse-forming electronics, structural support, and cooling equipment. Part of the desired reduction in the footprint of the system is predicated on the development of a sufficiently energy-dense pulse power source. In [2]-[3], the authors note that the theoretical ratio of energy density between state-of-the-art storage systems using either capacitors, inductors, or rotating machines is $1: 10: 100$, implying a strong advantage for kinetic-energy-based designs such as compensated pulsed alternators (compulsators). However as reported in [4], compulsator systems are quite complex and are challenging to fabricate and cool. At present, the energy storage function at the NSWC Dahlgren test facility is implemented using capacitor banks.

U.S. Government work not protected by U.S. copyright
Though being less technologically mature in the electromagnetic gun arena, it is believed that inductivebaseded energy storage (IBES) offers an attractive alternative to either capacitors or compulsators. By exploiting large achievable flux densities, IBES can be far more energy dense than capacitors. Further in comparison to compulsators, IBES is static, easier to cool, and can use a low-voltage prime power source [5]. However, energy is extracted from IBES by commutating the inductor current from a switch into a pulseshaping circuit. Thus an 'opening switch' must be able to repetitively interrupt the significant currents required by the gun.

Researchers at the Institute for Advanced Technology (IAT) at the University of Texas in Austin have proposed and investigated a circuit referred to as a "STRETCH meatgrinder," which employs a Gate-Turn-Off (GTO) thyristor as the opening switch as shown in Fig. 1 [2]. When the GTO turns on, energy is transferred from the DC power supply to the coupled inductors $\mathrm{L}_{1}$ and $\mathrm{L}_{2}$. As $\mathrm{SCR}_{1}$ is closed and the GTO switch opens, the current through $\mathrm{L}_{1}$ must decrease while the current through $\mathrm{L}_{2}$ increases, resulting in a pulse of current through the railgun barrel. The only path for the $\mathrm{L}_{1}$ current is through $\mathrm{C}_{1}$ which charges through $\mathrm{D}_{1}$. After some time, $\mathrm{SCR}_{1}$ closes, allowing $\mathrm{C}_{1}$ to discharge through $\mathrm{L}_{1}$ in reverse and through the railgun barrel. This provides a second pulse of current through the railgun.

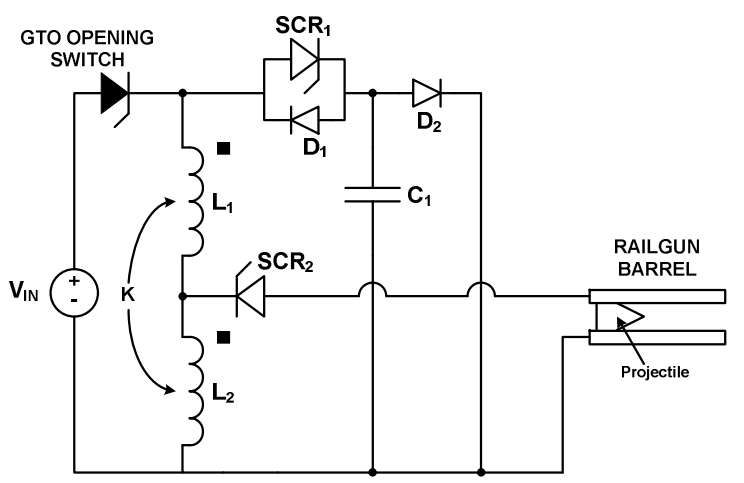

Fig. 1. Inductive-Based STRETCH Meat Grinder Pulsed-Power Supply 
In prototyping, it was reported to the authors that the IAT investigators found that a commercially-available GTOthyristor was able to interrupt significantly more current than advertised on the data sheets. Specifically, a part rated to repetitively turn off $3.8 \mathrm{kA}$ was able to successfully interrupt more than $7 \mathrm{kA}$. In another pulse forming network example reported in [6], the authors found that a GTO opening switch rated to interrupt $1.8 \mathrm{kA}$ was able to interrupt $3.2 \mathrm{kA}$ when operated at a low repetition rate. This paper seeks to build on these empirical results and further investigate the factors that might influence the current-interruption capability of the GTO in a pulsed-power application. By increasing the capability of the opening switch, higher-power inductivebased pulse forming networks may become more feasible for future railgun applications.

\section{TEST CIRCUIT}

\section{A. Overview}

The goal of this project was to experimentally examine the current interruption capability of a GTO thyristor as a function of the gate turn-off current in a pulsed-power application. As the actual output current pulse has no immediate relevance to the performance of a turn-off switch, the basic pulse-forming circuit shown in Fig. 2 was selected versus the more complex STRETCH meat grinder topology. The circuit operates as follows. Initially, the manual switch is closed and the high-voltage power supply is made to charge up the capacitor bank to some prescribed level. Upon user input, the FPGA-based controller would initiate the turn on of the GTO thyristor. The capacitor bank would then discharge through the inductor and generate a quasisinusoidal pulse of current through the GTO. At a desired anode current level, the controller will attempt to turn off the GTO with a user-adjustable pulse of gate current, causing the inductor current to free-wheel through the diode. A snubber is required across the switch to limit the rate-of-change of the turn-off voltage.

\section{B. Switch Selection}

The original target for this investigation was a $4500 \mathrm{~V}$ ABB GTO with a maximum interruptible current of $600 \mathrm{~A}$. At a cost of over $\$ 1 \mathrm{k} / \mathrm{switch}$, it was not financially practical to drive dozens of switches to failure. A compromise device was

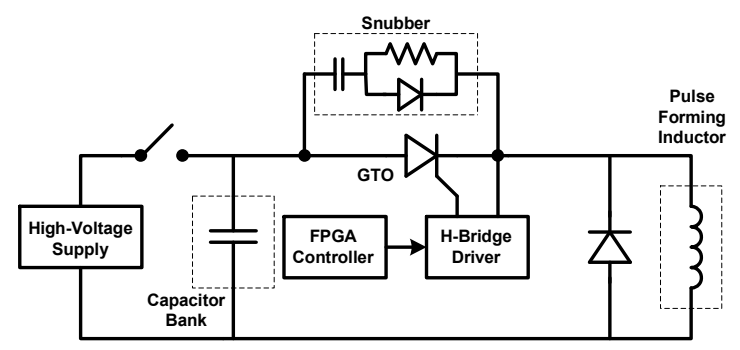

Fig. 2. Proposed Opening-Switch Test Circuit selected: a $1000 \mathrm{~V}$ Motorola MGTO-1000 in a TO-220 package with a maximum rated non-repetitive interruptible current of $70 \mathrm{~A}$ and a maximum surge current of $200 \mathrm{~A}$. Certainly, the currents considered here are orders of magnitude smaller than what is required in a full-scale railgun. However, the authors will assume that the resulting GTO device behavior presented in this work can scale to higher-rated devices.

\section{Parameter Selection}

A 350W, 500V Matsusada power supply was available for this project to charge the input capacitor bank. It was further decided to use a capacitor bank comprised of four Cornel Dubilier $450 \mathrm{~V}, 2400 \mu \mathrm{F}$, electrolytic capacitors connected in parallel and operate them at charging voltages ranging from $0 \mathrm{~V}$ up to $400 \mathrm{~V}$. The Electronics Workbench circuit analysis program Multisim was then used to size the required inductance and resistance of the pulse-forming coil. The goal was to achieve a time-to-peak-current of about $8 \mathrm{~ms}$ (representative of a railgun pulse-forming network condition), a maximum anode current of $250 \mathrm{~A}$ when the capacitor bank was charged to $400 \mathrm{~V}$, and a maximum fusing current of approximately $250 \mathrm{~A}^{2} \mathrm{~s}$. These values would ensure that there could be operating conditions that would lead to device failure. The inductance and resistance were sized to be $5 \mathrm{mH}$ and $1 \Omega$, respectively. The simulation data shown in Fig. 3 illustrate how the resulting peak anode current could be adjusted by varying the initial charge on the capacitor bank. These waveforms assume that the GTO switch is not turned off.

The RCD-snubber illustrated in Fig. 2 was comprised of a $470 \mathrm{nF}$ metalized polypropylene film capacitor with an ESR < $6 \mathrm{~m} \Omega$ and an ESL $<23 \mathrm{nH}$, a $600 \mathrm{~V}$ fast-recovery diode with a $200 \mathrm{~A}$ surge current capability, and a $1 \mathrm{k} \Omega, 2 \mathrm{~W}$ resistor. These values ensured that the turn-off voltage spike did not exceed the rated anode-cathode voltage, enabled the capacitor to discharge within $4 \mathrm{~ms}$ of GTO turn on, and limited the rate-ofchange of the switch voltage.

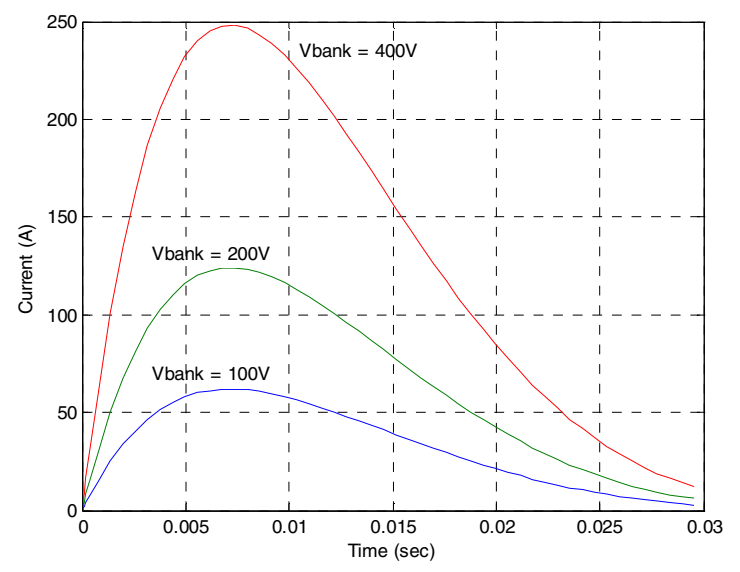

Fig. 3. Variation in the GTO Anode Current with Capacitor Bank Charge Voltage 


\section{GTO Gate Driver Specification}

The circuit shown in Fig. 4 was derived from work reported in [6] and was used to control the GTO turn on and turn off. The power supplies $\mathrm{V}_{\mathrm{ON}}$ and $\mathrm{V}_{\mathrm{OFF}}$ are used to independently control the initial voltages placed on $\mathrm{C}_{\mathrm{ON}}$ and $\mathrm{C}_{\mathrm{OFF}}$ and are then disconnected while the switch is being operated. Devices $\mathrm{M}_{1}$ and $\mathrm{M}_{3}$ are closed during turn on; devices $\mathrm{M}_{2}$ and $\mathrm{M}_{4}$ are closed during turn off. The small $(\sim 2.5 \Omega)$ resistors $\mathrm{R}_{\mathrm{ON}}$ and $\mathrm{R}_{\mathrm{OFF}}$ are included to control the peak current entering or exiting the GTO gate. Digital logic control signals were coupled to a Intersil HIP4082 driver chip using Fairchild Photodarlington Optocouplers. The driver chip then supplied the turn-on and turn-off gate signals for the four MOSFETs (selected to be IRF1010 50V power HEXFETs). Power was supplied to the driver using a $15 \mathrm{~V}$ isolated dc-dc converter from $\mathrm{V}$-infinity.

\section{E. External Control Circuit}

An external logic circuit, implemented on an Altera DE2 Development and Education Board, was used to control when the gate drive MOSFETs turned on and for how long. The DE2 board is a commercially-available FPGA that can be programmed in VHDL for various digitial electronic applications. There were four separate timing values that had to be input into the DE2 board: the delay time until the start of the turn-on pulse, the pulse width of the turn-on pulse, the delay time until the start of the turn-off pulse, and the duration of the turn-off pulse. At the end of the experiment the program resets the timing circuit and awaits the next circuit "shot." The program also checks for impractical values and disallows such experiments.

\section{F. Inductor Design}

The inductor shown in Fig. 2 was designed via simulation to have an inductance of $5 \mathrm{mH}$ and a resistance of $1 \Omega$. It was decided to implement it as an air-core wire-wound inductor. By tightly wrapping magnet wire around a PVC pipe, the coil inductance can be roughly approximated by the Wheeler formula shown in (1)

$$
L=\frac{r^{2} n^{2}}{9 r+10 l}
$$

where $\mathrm{n}$ is the number of turns, 1 is the coil axial length, and $\mathrm{r}$ is the average turn radius. The associated coil resistance

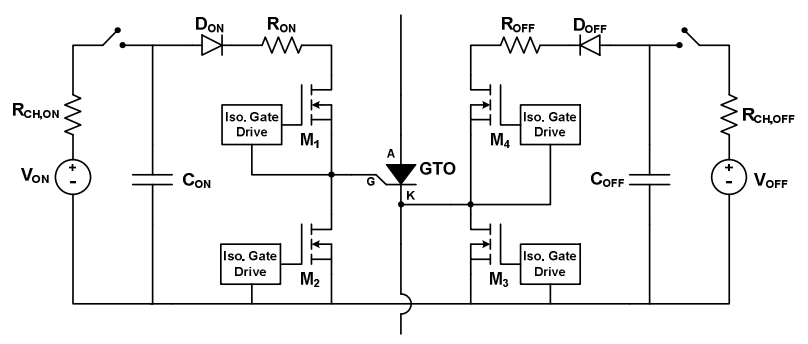

Fig. 4. GTO Thyristor Gate Drive Circuit given by

$$
R=2 \pi r n \rho
$$

where $\rho$ is the wire resistivity. Selecting a PVC pipe with outer diameter of 4.5 " and 16-gauge magnet wire resulted in a 4-layer solenoid of 2.715 " axial length with 209 turns. The measured inductance and resistance were $4.62 \mathrm{mH}$ and $1.03 \Omega$, respectively.

\section{G. Circuit Monitoring}

For these experiments, it was an imperative to record the GTO thyristor currents and relevant voltages, especially as component operation neared failure. The anode and gate currents are monitored using Rogowski current transducers. Power Electronic Measurements CWT Ultra Mini models were selected because they could be fitted around the gate and anode device terminals and introduced minimal stray inductance. Anode-to-cathode and gate voltages are measured using calibrated differential voltage probes that were connected to convenient solder points on the printed circuit board.

\section{H. Printed Circuit Board}

The most important factor considered during board layout was minimizing stray circuit inductances. This was largely accomplished by placing key components as physically close to one another as possible (for instance, gate drive MOSFETs and the GTO) and by employing a large ground plane for the common return of the capacitor banks. An image of the completed PCB is illustrated in Fig. 5.

\section{Representative Turn-Off Waveforms}

Representative turn-off voltage and current waveforms are illustrated in Fig. 6. At $\mathrm{t}_{0}$, a negative voltage is applied across the gate-cathode junction causing a linear decrease in the gate current at a rate dictated by the gate circuit inductance and the applied voltage. Cathode current is diverted to the gate as charge is swept out of the P-base region. At $t_{1}$ the GTO can no longer maintain "latch," and the anode current begins to decrease causing an increase in the snubber current. The

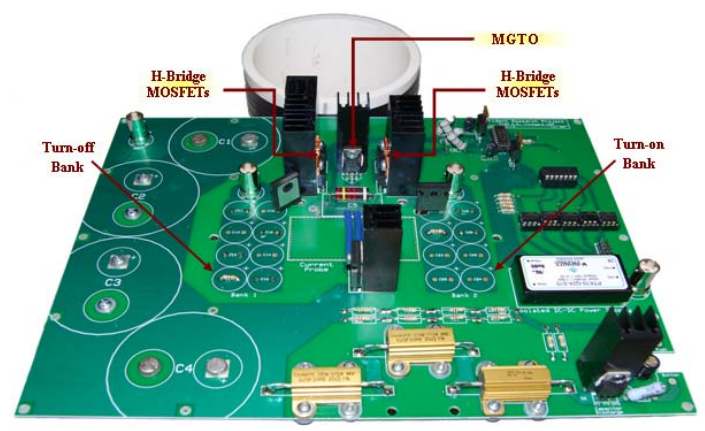

Fig. 5. Printed Circuit Board Layout 


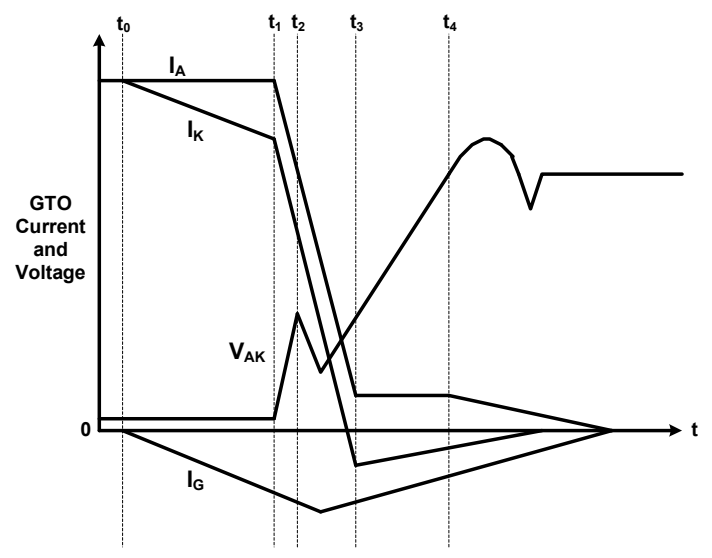

Fig. 6. Representative GTO Thyristor Waveforms at Turn Off

snubber current flows through the capacitor causing the anode-cathode voltage to start to build. Stray inductance associated with the snubber circuitry produces the characteristic spike in $\mathrm{V}_{\mathrm{AK}}$ that occurs at $\mathrm{t}_{2}$. At $\mathrm{t}_{3}$ the anode current enters its tail phase as the $\mathrm{N}$-base charge is removed by recombination. At $t_{4}$, the anode-cathode voltage continues to increase due to energy stored in the snubber inductance releasing into the snubber capacitance.

\section{EXPERIMENTAL PROCEDURE}

The experiments proceeded as follows: the capacitor bank shown in Fig. 2 was charged to a level required to achieve a desired peak switch current (see Fig. 3). With the interrupting current held constant at this value, the voltage on the capacitor bank associated with the gate turn-off current $\left(\mathrm{C}_{\mathrm{OFF}}\right.$ in Fig. 4) was then adjusted to determine the minimum gate current required to successfully turn off the GTO thyristor. For each test condition, the anode and gate currents are monitored and stored in the oscilloscope along with the anode-cathode voltage and the gate voltage. The data was then exported to MATLAB for post-processing in order to compute the peak gate current, the turn-off gate charge, the anode-cathode rate-of-change of voltage, and the rate-ofchange of anode current during turn off. The next phase of experimentation entailed holding the turn-off gate current peak constant and iteratively adjusting the anode current interruption level by adjusting the voltage on the input capacitance bank. The same two sets of currents and voltages are monitored and recorded. A Safe Operating Area (SOA) can then be assembled by concatenating the two results. Finally, the two sets of experiments are repeated for a second value of snubber capacitance to determine how its value impacts the boundary.

\section{EXPERIMENTAL RESULTS}

The results of this investigation are summarized in Fig. 7. Data was taken for 14 different anode currents to establish the minimum permissible gate current that could still interrupt

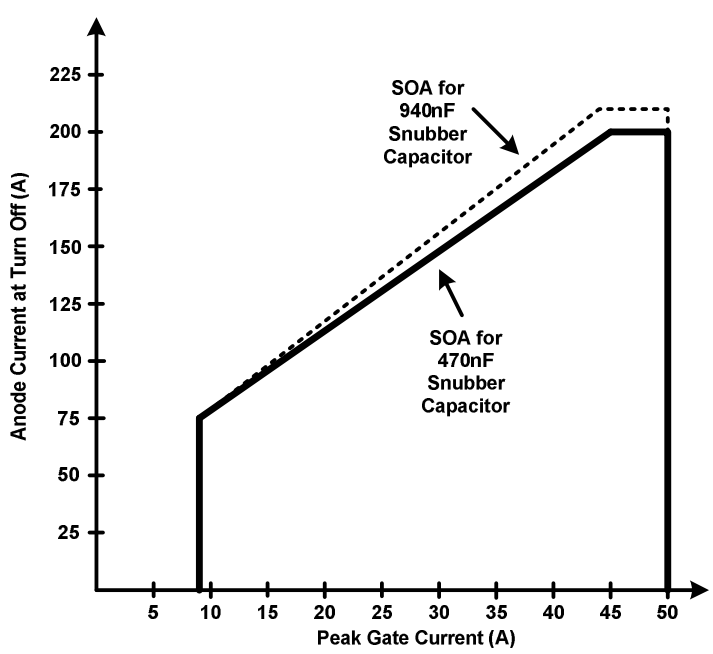

Fig. 7. Experimentally-Derived GTO Turn-Off Safe Operating Area

the given anode current. Next, data was taken for 20 different gate currents. Here the gate current was held constant and the anode current was increased until the device failed to turn off. The "approximate" SOA shown in Fig. 7 indicates that with large gate currents at turn off, very large anode currents can be interrupted. Specifically, the GTO was able to be turned off up to the surge current rating of the device, much higher than the $70 \mathrm{~A}$ maximum rated non-repetitive interruptible current, similar to the claim made in [6]. The experiments were then repeated with the snubber capacitance doubled from $470 \mathrm{nF}$ to $940 \mathrm{nF}$. This increase in capacitance which will tend to slow the rate-of-change of the anode-cathode voltage across the switch and lengthen the turn-off time, had a very slight effect on the SOA, yielding an ability to turn-off slightly larger anode currents for a specific value of peak gate current.

\section{DISCUSSION OF FAILURE MECHANISM}

GTO thyristor turn-off failure has been investigated and reported frequently in the literature, though most applications are at much higher repetition rates (switching frequencies) than what a railgun will demand. In part, the device failure can be visualized by referring to Fig 8 . When current starts to be extracted from the gate terminal, the stored P-base charge will first be removed from the area closest to the gate contact. After this region turns off, the gate current removes charge a bit further inwards of the device and initiates a constriction of the cathode current towards the center of the $\mathrm{N}^{+}$emitter, creating what is called a current filament. This "current crowding" can lead to localized heating and device failure. In Jaecklin \& Adam [8], the authors postulate that the failure mechanism in GTOs at turn off is due to an uneven turn-off of the various GTO units ( 1000 per device). The turn-off current is concentrated in a few cells and if a sufficient anode-cathode voltage is concurrent, then dynamic avalanche will occur and the device will frequently be destroyed. Cell 


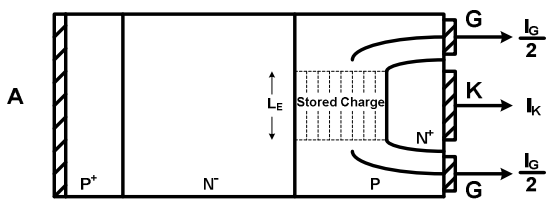

A

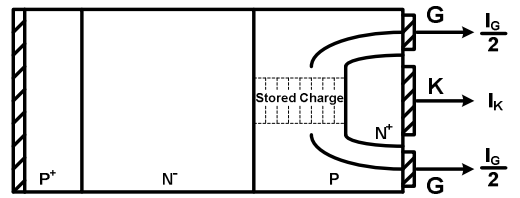

A

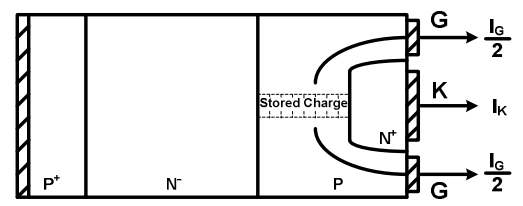

Fig. 8. Illustration of Current Crowding in a GTO at Turn Off

differences were said to arise due to local differences in technology parameters like carrier lifetime, injection efficiency, and transport factor.

In Yatsuo [9], the authors argue that current crowding is specifically a function of the non-uniform distribution of the on-state current between the many GTO units caused by (1) differences in average on-state voltages and (2) differences in contact voltage drop between the unit GTOs and the cathode. In Bakowski [10], the authors attempt to model the formation of the current filament during the fall time of the GTO turn off. The authors describe two failure modes. First, an uncontrollable current generation can result as the gate cannot absorb the extra current, the device is locally retriggered, and failure occurs from the stress induced by the inductive voltage spike $\mathrm{V}_{\text {DSP. }}$. The second failure mechanism is termed dynamic avalanche, where the cathode junction is forward biased by the lateral base current. They specify that a large tail current is required for this mechanism to dominate.

Finally in [11], failure is described in these terms: (1) dynamic avalanche will occur at the point that $V_{\text {DSP }}$ occurs, (2) the localized avalanche area will form a hot spot, (3) when the hot spot reaches the intrinsic temperature of silicon, thermal run away will initiate, and (4) the time delay between the voltage spike and the voltage breakdown is due to the thermal time constant of the thermal run away. Though representing building consensus, this explanation does not quite explain why physically devices have superior current interruption capability in pulsed-power applications. There remains a need to couple the circuit operational conditions to the semiconductor physical model and investigate the resulting device thermal performance.

\section{CONCLUSION}

This paper has experimentally demonstrated that GTO thyristors have a higher capacity for current interruption when they are used in a pulsed-power source. A specific test circuit was documented which enabled the researchers to test GTO turn off in a circuit environment similar to a railgun employing inductive-based energy storage. It was shown that a typical GTO was able to interrupt nearly three times the maximum interruptible current, up to the rated surge current of the device. Follow-on work might investigate the impact of repetition rate on device failure, assessing the role, if any, that thermal cycling might play in a typical pulsed-power application. The conduction time for the GTOs was limited to about $6 \mathrm{~ms}$ in these experiments (see Fig. 3). The impact of extending this time could also be investigated. Finally, additional modeling using Silvaco/Atlas might be conducted to further elucidate the physical cause of device failure. The ultimate goal of such research is to be able to produce highpower devices designed specifically with enhanced turn-off capability for use in railgun systems.

\section{ACKNOWLEDGMENT}

The authors would like to thank Ensign Gerald Vineyard, whose Trident Scholar project was the basis for this paper. Ensign Vineyard performed all of the data collection and, with limited supervision, developed all of the required hardware fixtures and VHDL software.

\section{REFERENCES}

[1] United States Naval Research Advisory Committee Panel on Electromagnetic (EM) Gun Technology Assessment, "Electomagnetic (EM) Gun Technology Assessment," Office of the Assistant Secretary of the Navy - Research, Development, and Acquisition, 2004.

[2] A. Sitzman, D. Surls, and J. Mallick, "Design, Construction, and Testing of an Inductive Pulsed-Power Supply for a Small Railgun," IEEE Trans. On Magnetics, Vol. 43, No. 1, Jan. 2007, pp. 270-274.

[3] M. D. Driga, "Asynchronous Generators for Fast, High-Energy Pulsed Discharge as Power Supplies for Electromagnetic Launchers," $9^{\text {th }}$ Intern. Pulsed Power Conference, Jun 1993, Vol. 1, pp. 196-202.

[4] I. R. McNab, "Developments in Pulsed Power Technology," IEEE Trans. On Magnetics, Vol. 37, No. 1, Jan. 2001, pp. 375-378.

[5] M. Kanter, A. Pokrvailo, N. Shaked, and Z. Kaplan, "Factors in Inductive Storage System Design," $10^{\text {th }}$ Intern. Pulsed Power Conference, Jul 1995, Vol. 1, pp. 186-191.

[6] M. Kanter, S. Singer, R. Cerny, and Z. Kaplan, "Multikilojoule Inductive Modulator with Solid-State Opening Switches," IEEE Trans. On Power Electronics, Vol. 7, No. 2, 1992, pp. 420-424.

[7] O. Despe and J. Wang, "A Gate Drive Circuit for Gate-Turn-Off (GTO) Devices in Series Stack," Proc. Of the 1999 Particle Accelerator Conf., Vol. 5, pp. 3773-3775.

[8] A. Jaecklin and B. Adam, "Scaling Laws and Performance Limitations of Power Turn-Off Devices," Power Electronics Specialist Conference (PESC) 1989, pp. 337-342.

[9] T. Yatsuo , S. Kimura, and Y. Sato, "Design Considerations for LargeCurrent GTO's," IEEE Trans. On Electron Devices, Vol. 36, No. 6, 1989, pp. 1196-1202

[10] M. Bakowski and U. Gustafsson, "The Two Basic Failure Modes in the GTO - Modeling and Experiment," Intern. Symp. On Power Semiconductor Devices \& ICs, 1995, pp. 354-368.

[11] M. Duta and E. Cretu, "Investigations of Avalanche Dynamics in IGBTs, Bipolar GTOs, and MCTs," $17^{\text {th }}$ Telecommunications Energy Conference (INTELEC)1995, pp. 340-345. 